\title{
TEJIENDO LA VIDA EN LA CIUDAD DE CALI Estrategias de adaptación e inclusión de seis cabildos indígenas urbanos
}

Nancy Motta González••

\begin{abstract}
Resumen
Este trabajo se propone establecer la relación entre procesos que se han denominado de "construcción étnica" (Koonings y Silva, 1999) o "reinvención étnica" (Castillo y Cairou 2002:66) y las estrategias de supervivencia que establecen seis grupos étnicos en la ciudad de Cali. Se trata de ver de qué manera los seis cabildos indígenas urbanos en la ciudad de Cali han emprendido procesos políticos, para reivindicar su diferencia étnica y los derechos que les asisten como indígenas, han utilizado esta diferencia para obtener alguna ventaja en la actividad económica que desarrollan, las rutas migratorias y su relación cabildo indígena rural-urbano, como un continuum del resguardo y la ciudad y las formas apropiadas de reinvención étnica en lo simbólico en el espacio urbano, y la estrategia política de alianza multiétnica.
\end{abstract}

Palabras clave: identidad étnica, construcción étnica, reinvención étnica, grupos étnicos urbanos, cabildos urbanos, alianza multiétnica.

\begin{abstract}
The aim of this work is to state the relationship between processes that have been called "of ethnicity building" (Koonings and Silva, 1999) or "ethnic reinvention" (Castillo and Cairou, 2002:66) and the strategies of survival that employ six ethnic groups in the city of Cali. An exam is made of the ways in which the six urban indigenous Cabildos have undertaken political processes for asserting their ethnic differences and the rights on which they are based as indigenous peoples, and the uses they have made of Duch differences for obtaining advantages in the economic activities that they develop, as well as of the migrant paths and of the relationships between the urban and the rural Cabildos, as a continuum of the Resguardo and the city, and of the adequate ways of ethnic reinvention in the symbolic dimension of the urban environment, and the political strategy of multi-ethnic alliance.
\end{abstract}

Key words: ethnic identity, ethnicity building, ethnic reinvention, urban ethnic groups, urban cabildos, multi-ethnic alliance.

Introducción

El Estudio Etnológico de las Comunidades Indígenas ubicadas en el municipio de Cali hace parte de un proceso que vienen adelantando las comunidades indígenas asentadas en la ciudad de Santiago de Cali (Colombia) desde finales

\footnotetext{
- Artículo tipo 2, de reflexión según Colciencias. Resultado parcial de la investigación "Estudio etnológico de las comunidades indígenas ubicadas en el municipio de Cali (Ingas, Kofanes, Quichuas, Yanaconas, Nasas y Guambianos)".

- Antropóloga de la Universidad del Cauca con Maestria en Desarrollo Rural de la Pontificia Universidad Javeriana. Jefa del Departamento de Historia de la Universidad del Valle, Exdirectora y miembro del Centro de Estudios de Género, Mujer y Sociedad, miembro del grupo Region de la Facultad de Humanidades Universidad del valle. E-mail: namogon@ univalle.edu.co
} 
de la década de los 90 en busca de su reconocimiento ante las instituciones del orden nacional, regional y local.

El proyecto se llevó a cabo en el marco de un convenio suscrito entre la Alcaldía de Santiago de Cali y el Ministerio del Interior en el que, para dar respuesta a las solicitudes de las comunidades indígenas, el gobierno de la ciudad decide adelantar un estudio de las 6 comunidades que hasta el momento se han organizado como cabildos urbanos (Quichua, Inga, Kofán, Guambiano, Nasa y Yanaconas) bajo las directrices del Ministerio. Con este objetivo se estableció un convenio entre la Alcaldía municipal de Santiago de Cali y la Fundación General de Apoyo a la Universidad del Valle para realizar la investigación. El equipo de investigación se conformó con profesores investigadores de tres unidades académicas de la Universidad del Valle (Departamentos de Historia, Sociología y Geografía), estudiantes de estas unidades académicas y profesionales externos. Así mismo, se conformó un equipo de dinamizadores de las seis comunidades indígenas que hicieron parte del equipo de investigación como informantes clave, de apoyo a las labores de investigación y como encuestadores.

De acuerdo con los términos de referencia y los lineamientos propuestos por la Subdirección de Etnias del Ministerio del Interior la investigación fue realizada a partir de tres componentes, en primer lugar, el Componente Sociodemográfico implicó la realización de un censo de los miembros de cada cabildo; en segundo lugar, el Componente Etnográfico consistió en la realización de trabajo de campo y etnografías de cada comunidad y, por último el Componente Sociojurídico significó el análisis de la situación jurídica de cada cabildo y el estudio en general de la jurisprudencia relacionada con la situación de los indígenas en la ciudad con el fin de emitir un concepto jurídico al respecto.

La investigación que se desarrolló sobre cada cabildo, implicó desde el punto de vista metodológico, la combinación de una estrategia cuantitativa y una estrategia cualitativa, así como un trabajo interdisciplinario desde la antropología, la sociología, la geografía y el derecho. La estrategia cuantitativa conllevó a la aplicación de una encuesta a todos los miembros de las comunidades reportados por cada cabildo, esta encuesta estaba dividida en dos partes, una primera que incluía las preguntas sobre indicadores sociodemográficos y correspondía propiamente a las que se realizan en un censo, y una segunda parte que hacía referencia a algunos aspectos de las prácticas socioculturales de construcción de comunidad en la ciudad y sobre el proceso migratorio, que era análoga a lo que se conoce como una encuesta especializada. A partir de la identificación de la dirección de los hogares se procedió a espacializar cada una de las comunidades en el plano de la ciudad de acuerdo con las subdivisiones administrativas y la estratificación social, también se contrastó esta localización con las áreas de influencia de determinados equipamientos sociales como los educativos y de salud, y respecto a amenazas naturales. En la estrategia cualitativa, de un lado, se hicieron entrevistas a los gobernadores, cabildantes y líderes de las comunidades, y por otro, se realizaron visitas domiciliarias a un número limitado de familias en las que se aplicaron entrevistas a algunos de los 
miembros de la familia, se hizo observación etnográfica tanto en distintos eventos organizados por los cabildos en la ciudad y en las asambleas a las que los/las investigadores/as tuvieron la oportunidad de asistir, como también observación en cada una de las familias muestreadas de los seis cabildos para entender su situación social, económica y de infraestructura en la ciudad. Para el componente jurídico se solicitó a cada uno de los gobernadores una serie de documentos necesarios para estudiar la situación jurídica de cada cabildo.

El presente documento es el resultado de la investigación, donde se muestra de manera sintética las estrategias de adaptación e inclusión que han desarrollado los indígenas en la ciudad y cómo han construido la vida, organizado su estructura social étnica y redefiniendo su identidad en la ciudad.

\section{El contexto regional y municipal y los grupos étnicos en Cali}

\subsection{Aspectos demográficos}

De acuerdo con el Censo Nacional del $2005^{1}$, la población colombiana ascendía a 41.468 .384 habitantes de las cuales apenas un $3.4 \%$ se autorreconocieron como indígenas es decir 1.378 .884 personas, no obstante su relativo bajo peso en el total de la población del país, los indígenas se han constituido como un actor social de primer orden en la historia reciente del país. En la década del 70 del siglo pasado, los indígenas en un movimiento social que tuvo su epicentro en el departamento del $\mathrm{Cauca}^{2}$ iniciaron un proceso de recuperación de sus tierras ancestrales. Posteriormente en las décadas 80 y 90 los indígenas de este departamento lideraron un amplio movimiento de resistencia civil contra la guerra y la violencia estructural ${ }^{3}$ de los que han sido víctimas. Por ello el papel importantísimo de éstos en la promulgación de la Constitución de 1991, que surge como un acuerdo de paz en el que estuvieron involucrados todos los actores sociales. En esta constitución se reconoce el carácter de nación diversa, multiétnica y pluricultural de Colombia y como desarrollo de su contenido se legislan los derechos territoriales sobre las tierras ocupadas ancestralmente por las poblaciones afrocolombianas, así como normas que promueven el fortalecimiento de los resguardos y cabildos indígenas, y toda una normativa en pro de la inclusión social de los grupos étnicos existentes en el país.

El Valle del Cauca representa el 1,9\% del territorio colombiano y el $9,9 \%$ de la población colombiana (4.240.653 habitantes). Es un departamento esencialmente urbano ya que el $87 \%$ de sus habitantes viven en la zona urbana y el restante $13 \%$ en la rural. Es el departamento que más ciudades intermedias tiene en Colombia, con más de 190.000 habitantes. 14 ciudades de las 83 principales ciudades del país se localizan en el Valle del Cauca, por

\footnotetext{
${ }^{1}$ Este censo fue realizado por el Departamento Administrativo Nacional de Estadística, DANE.

2 El departamento del Cauca ocupa el segundo a nivel nacional en volumen de población indígena después de La Guajira.

${ }^{3}$ La violencia estructural es definida en términos de las condiciones de vida precaria resultantes de la discriminación racial y la exclusión social de la que han sido víctimas los grupos étnicos en Colombia.
} 
eso es llamado el departamento de ciudades. Contribuye con el $11,9 \%$ del PIB del país, y el 16\% del PIB manufacturero nacional (CVC - Univalle,2007)

Cali, su capital, concentra el $51 \%$ de la población del Valle del Cauca y genera más de la mitad del valor agregado y del empleo del departamento, y se agrupa aproximadamente el $70,6 \%$ de su población urbana. Es la tercera ciudad del país, principal centro comercial y financiero del Suroccidente Colombiano y primer polo del corredor urbano que se extiende entre Popayán y el Eje Cafetero. Cuenta con una población de 2.119.908 habitantes y con una población que se autoidentifica étnicamente como mestiza $73.10 \%$, negra $26.4 \%$ e indígena $0.5 \%$ que corresponde a 10.341 personas. (Alcaldía Municipal, 2001).

De acuerdo con datos de la encuesta anual manufacturera del DANE en 2003 la actividad económica de la ciudad se distribuyó de la siguiente manera: el $54,0 \%$ de los establecimientos correspondieron a entidades dedicadas al comercio, el $29,6 \%$ a servicios, el $9,3 \%$ a la industria, y el $7,1 \%$ a otras actividades, no obstante la actividad que genera mayor valor agregado en la ciudad es la industria con una participación en el valor agregado promedio de la economía local en la última década del $30 \%$, en segundo lugar están las actividades dedicadas a los servicios con un $18 \%$ de participación, seguidas por la construcción (10\%) y la intermediación financiera (10\%) (Bonilla y Rodríguez, 2003, p. 7)

Los departamentos de los que provienen los indígenas inmigrantes a la ciudad de Cali son Cauca, Nariño y Putumayo, situados en el suroccidente del país al sur del departamento del Valle. Estos departamentos comparten la característica de concentrar mayores porcentajes de población indígena del país y de diversidad étnica, cuya población sumada corresponde a la tercera parte del total de la población indígena en Colombia. Cali como ciudad que configura el área metropolitana ${ }^{4}$ más importante del suroccidente colombiano no sólo es el centro de atracción de la inmigración rural urbana de los departamentos vecinos, sino uno de los sitios de llegada de los desplazados por el conflicto armado interno que vive el país. Los tres departamentos mencionados son expulsores netos de población, con un menor nivel de desarrollo, menores tasas de urbanización y peores condiciones de vida respecto a este último, si se comparan los porcentajes de población en hogares con necesidades básicas insatisfechas del Valle con los porcentajes respectivos de Cauca, Nariño y Putumayo como se puede observar en la tabla 1.

\footnotetext{
${ }^{4}$ Con cerca de 2.500 .000 habitantes.
} 
Tabla 1

Datos de Población total e indígena de Valle, Cauca, Nariño y Putumayo para 2005

\begin{tabular}{|l|r|r|r|r|l|l|}
\hline Departamento & $\begin{array}{l}\text { Población } \\
\text { Total }\end{array}$ & $\begin{array}{l}\text { \%Población } \\
\text { urbana }\end{array}$ & $\begin{array}{l}\text { \% } \\
\text { Hogares } \\
\text { con NB|}\end{array}$ & $\begin{array}{l}\text { Población } \\
\text { Indígena }\end{array}$ & $\begin{array}{l}\text { Nro } \\
\text { etnias }\end{array}$ & $\begin{array}{l}\text { \% Pob } \\
\text { ind } \\
\text { Tot pob. }\end{array}$ \\
\hline Valle & 4.461 .425 & 86.4 & $15.6 \%$ & 21.845 & 5 & 0.5 \\
\hline Cauca & 1.268 .937 & 38.0 & $46.4 \%$ & 247.987 & 9 & 19.5 \\
\hline Nariño & 1.541 .956 & 45.6 & $43.8 \%$ & 154.776 & 6 & 10.0 \\
\hline Putumayo & 310.132 & 43.7 & $34.8 \%$ & 37.896 & 10 & 12.2 \\
\hline
\end{tabular}

www.dane.gov.co

NBI: Necesidades básicas insatisfechas.

Si bien los datos del Censo nacional del 2005 apuntan a que más de 10.000 personas se autorreconocieron como indígenas en la ciudad, el número de los que están organizados en cabildos es muy inferior. El censo realizado por los 6 cabildos indígenas en el año 2003 (Secretaría de Desarrollo Territorial, 2003) arrojaba la cifra de 2078 personas adscritas a estos cabildos, posteriormente en el año 2006 los mismos cabildos se autocensaron determinándose un total de 4.185 personas (Secretaría de Desarrollo Territorial, 2006). La presente investigación realizó el censo a los 6 cabildos indígenas urbanos en el año 2007, encontrándose un total de 3.635 personas (Motta y Posso, 2007).

\section{Los grupos étnicos estudiados}

La primera característica que podemos señalar sobre la población indígena de la ciudad de Cali es su diversidad étnica, pues además existen otros grupos étnicos no organizados como cabildos. De acuerdo a sus lugares de origen, los seis grupos étnicos investigados pueden clasificarse en términos geográficos de la siguiente manera:

1) los procedentes de la zona andina específicamente los pueblos ubicados sobre la cordillera central del departamento del Cauca, como los Nasa, los Namui Misag (Guambianos) y los Yanaconas; 2) una zona intermedia o puente entre la selva amazónica y los andes donde se ubican Ingas y Kofanes que provienen de los departamentos de Putumayo y Nariño; 3) los Quichuas originarios de la zona andina del Ecuador principalmente de las regiones de Imbabura (Otavalo) y Chimborazo (Riobamba).

Una segunda característica es que Nasas, Guambianos o Namui Misag, Yanaconas, Ingas y Kofanes comparten la historia común de habitar en zonas de expansión de los cultivos ilícitos, áreas en disputa territorial entre la guerrilla y el paramilitarismo, que en distintos momentos ha afectado a cada grupo. Al igual que los demás grupos étnicos en Colombia, han residido en territorios con bajas condiciones de vida en cuanto a servicios sociales e infraestructura de comunicaciones, con relación a la mayoría de la población, situación ésta denominada por Essed (1991) como racismo institucional o racismo indirecto (Wade, 1987) y otros, violencia estructural. Los Quichuas también han sufrido racismo, pues la estructura social ecuatoriana es semejante a la de Colombia. 
2. Aspectos socioculturales, económicos y políticos

2.1. El continum resguardo - cabildo urbano y las prácticas culturales en Cali

La causa principal de la inmigración de la población indígena de los seis cabildos urbanos estudiados, es en primer orden (Tabla 2 ) la búsqueda de oportunidades de trabajo que no se encuentran en los territorios de origen, los porcentajes oscilan entre el 20 y el $70 \%$ de los hogares. Una segunda causa, son las razones familiares; los primeros inmigrantes que llegaron desde los años 60s hasta los más recientes en la década de los noventas a Cali, están mostrando un proceso migratorio que tiene su propia dinámica a través de las redes familiares, y que se mueve entre porcentajes que van del 10 al $30 \%$. También se debe resaltar que en la historia más reciente del país la violencia y el desplazamiento forzado es otra causa de movilidad espacial para todos los cabildos, exceptuando el Quichua. Ello se evidencia en los hogares de los cabildos Kofán, Guambiano, Nasa e Inga con valores respectivos del $42.1 \%$, $20.0 \%, 17.8 \%$ y $10,4 \%$. Una tercera causa de migración hacia la ciudad de Cali tiene que ver con las oportunidades educativas que brinda la ciudad al contar con los centros educativos de nivel superior de alta calidad en la región, lo que ha sido muy importante especialmente para los comuneros de los cabildos Guambiano o Namui Misag y Kofán.

Tabla 2. Motivo por el cual llega el hogar a la ciudad de Cali por cabildo

\begin{tabular}{|l|r|r|r|r|r|r|}
\hline \multicolumn{7}{|c|}{ Motivo por el cual llega el hogar a la ciudad de Cali } \\
\hline Motivo/Cabildo & Yanacona & Nasa & Quichua & Inga & Kofán & Guambiano \\
\hline Trabajo & 70,4 & 61,7 & 66,7 & 49,3 & 21,1 & 35,0 \\
\hline Estudio & 3,3 & 5,0 & 0,0 & 9,0 & 15,8 & 27,5 \\
\hline $\begin{array}{l}\text { Violencia o } \\
\text { desplazamiento } \\
\text { forzoso }\end{array}$ & 7,6 & 17,8 & 0,0 & 10,4 & 42,1 & 20,0 \\
\hline Razones familiares & 15,8 & 11,6 & 28,6 & 22,4 & 10,5 & 12,5 \\
\hline Motivos de salud & 0,7 & 1,7 & 0,0 & 0,0 & 5,3 & 0,0 \\
\hline $\begin{array}{l}\text { Ninguna de las } \\
\text { anteriores }\end{array}$ & 2,3 & 2,0 & 4,8 & 7,5 & 5,3 & 5,0 \\
\hline No sabe/no responde & 0,0 & 0,3 & 0,0 & 1,5 & 0,0 & 0,0 \\
\hline Total & 100,0 & 100,0 & 100,0 & 100,0 & 100,0 & 100,0 \\
\hline
\end{tabular}

Fuente: Motta, Posso, Estudio Etnológico, 2007. Trabajo de campo.

Por ejemplo, las razones por la cuales los ingas de Santiago migran a la ciudad de Cali son: su tradición andariega en busca de recursos y nuevos lugares de intercambio comercial y medicinal, y la falta de recursos económicas y oportunidades de empleo o educación en el Valle de Sibundoy. En la siguiente cita se describe la forma cómo empezaron a salir los ingas de su comunidad hacia otras zonas del territorio nacional y hacia países vecinos: 
Yo pienso que si, pero cuentan los mayores porque ellos son caminantes que van de ciudad de ciudad, antes ellos los llamaban, gente que conocía a los médicos tradicionales, los llamaban, los buscaban y los llevaban a partes lejanas, se iban por 15 días, un mes, y así empezaron a llegar a las diferentes ciudades, allí empezaron a trabajar y vender esa medicina tradicional, entonces ellos fueron viendo que les iba bien, que en la ciudad les creían y los llamaban para curar a los enfermos, eso les fue gustando a la ciudad y se fueron quedando, por eso parece que si ha sido una tradición salir a los pueblos, cuando hay mercados ellos van y venden lo que cultivan, venden pollos y todo lo que cultivan: arveja, maíz, lo poco, porque no es en una cantidad grande que sacan, pero si poquito como dicen ellos para comprar la sal y la manteca y además de eso venden lo que es las plantas medicinales, yo digo que eso es una tradición, los mayores cuentan que así empezaron los mayores a llegar de ciudad en ciudad y después se amañaron y no quisieron volver y se quedaron en la ciudad. (Entrevista con Isabel Chasoy).

Tanto las entrevistas en profundidad realizadas, como el censo indígena muestran que entre las principales motivaciones que han llevado a los Ingas de Mocoa y Aponte a migrar a la ciudad de Cali se encuentran el mejoramiento del trabajo y el empleo, favorables condiciones materiales de vida, el acceso a la educación y también la huida de la violencia, recientemente liderada por los actores de la guerra.

Las siguientes narrativas dan cuenta de esta situación migratoria:

Yo hace muchos años me vine de Mocoa, mi lugar de origen por la situación que existía allá, había mucha violencia y yo tenía mis hijos muy pequeños y mi esposo, entonces decidimos venirnos para Cali, llegamos y acá conocí donde estaba el cabildo y ya empecé a unir con ellos, a trabajar, me vine básicamente por la situación difícil. (Entrevista con Emerita Mavisoy).

Yo llegué hace 20 años a Cali por la necesidad de trabajar para dar estudio a mis hijos, vine a trabajar, para mejorar mi tierra que estaba muy abandonada, primero le di estudio a mis hijas pero ellas no quisieron estudiar, después estudiando Carlos de primero hasta quinto de primaria, luego hasta el sexto de bachillerato le ayudé; a mí me parece que la mejor herencia que uno le puede dar a sus hijos es el estudio, a mí me ha gustado porque Carlos me ha ayudado, cuando tenía su cargo en la alcaldía en Santiago recibía su plática cada mes y me ayudaba, los otros hijos me han ayudado cuidando la casa y las cosas que tengo en la finca. (Entrevista con José Jacanamejoy).

Para la etnia Nasa la migración comienza en la década de los 70 s cuando el Consejo Regional Indígena del Cauca-CRIC, inicia su proceso de reivindicación del derecho propio y empieza a recuperar sus territorios en manos de los terratenientes y hacendados de Popayán. Este hecho social 
implica que la fuerza pública defienda los terrenos de los grandes hacendados y reprima a los indígenas Nasas. Muchas familias salen de sus territorios de huida de la confrontación, sobre todo mujeres con sus hijos.

Luego en la década de los 80s, el desastre natural, la avalancha del río Páez sobre el costado oriental de Tierradentro, produce una segunda oleada migratoria hacia Cali y hacia terrenos rurales del Valle de Cauca. En estos dos periodos, años 70 y 80 son las mujeres quienes migran hacia Cali en calidad de empleadas domesticas, con la esperanza de adquirir ingresos para ellas y para sus familias.

Una tercera oleada se constituye a partir de un grupo de mujeres que llegan a la ciudad, traídas por familiares para buscar mejor oportunidades económicas y de estudio.

Una cuarta oleada ocurre en los años 90 s como consecuencia de la violencia generada por los actores armados, desplazando un buen contingente de Nasas, también en su mayoría mujeres.

Las entrevistas a profundidad nos relatan esta dinámica migrante:

Yo nací en Tierradentro, Inzá Cauca, estudie y fui formado por el sistema que nos rige allá que son cabildos donde estamos muy apoyados por la gente de allá, estuve en Inzá alrededor de 10 años, luego me fui para Belalcázar, que queda a 45 minutos más adentro, por eso se dice Tierradentro, ahí empecé el bachillerato y después me fui hacer una formación a Bogotá enviado por los cabildos a estudiar a Bogotá, estuve estudiando allá filosofía y letras, termine, me vine a seguir trabajando con la comunidad Páez, trabajé en el hospital por un periodo de 15 años pero sin desvincularme con el proceso que teníamos, en el hospital era el pagador de la entidad, pero nunca me desvincule de nuestro sistema que era el fortalecimiento de nuestros cabildos indígena. Aquí llegue hace 13 años. (Entrevista con Cesar O).

Yo nací en el resguardo indígena de San Andrés de Pisimbalá, Tierradentro en el departamento del Cauca. En Cali viví hace 5 años, vengo de vivir más o menos 14 años en Bogotá. Salí de mi resguardo de origen por la situación económica porque trabajé con una familia allá 14 años y ellos se vinieron para acá y me dieron la oportunidad de trabajar en una empresa, decidí venirme y también porque estaba más cerca de mi territorio. (Entrevista con Adriana V).

En la tabla 3 el contacto de los comuneros con el sitio de origen es muy estrecho, todos los porcentajes están por encima del $70 \%$, a pesar de la antigüedad del proceso migratorio como es el caso de la población de los cabildos Yanacona y Nasa, o pese a la distancia geográfica como ocurre con Quichuas y Kofanes que presentan los porcentajes más altos de hogares en los que algún miembro del hogar viaja al sitio de origen. 
Tabla 3. Viaje de algún miembro del hogar al resguardo de origen por cabildo

\begin{tabular}{|l|r|r|r|r|r|r|}
\hline \multicolumn{6}{|c|}{ Viaje de algún miembro del hogar al resguardo de origen } \\
\hline Cabildo & Yanacona & Nasa & Quichua & Inga & Kofán & Guambiano \\
\hline Si & 76,0 & 70,7 & 85,3 & 72,3 & 81,8 & 79,1 \\
\hline No & 24,0 & 29,3 & 14,7 & 27,7 & 18,2 & 20,9 \\
\hline Total & 100,0 & 100,0 & 100,0 & 100,0 & 100,0 & 100,0 \\
\hline
\end{tabular}
campo.

Fuente: Motta, Posso, Estudio Etnológico, 2007. Trabajo de

Las relaciones de los cabildos indígenas urbanos con sus territorios de origen es alta, y ello se manifiesta en las frecuencias de viaje a lo largo del año, como se observa en la tabla 4, y ello constituye una manera de contribuir a la preservación de las tradiciones culturales. Igualmente la noción de territorio ha quedado guardada en la memoria de estos migrantes, por tanto el arraigo al territorio tiene una significación cultural y ello no es incompatible con los fenómenos migratorios de la población joven.

La memoria histórica, la tradición oral son aspectos de continuidad de la cultura de estos grupos étnicos y ello se reactualiza permanentemente con los viajes que realizan a los resguardos y cabildos de origen.

Tabla 4. Frecuencia de viaje al resguardo de origen de algún miembro del hogar por cabildo

\begin{tabular}{|l|r|r|r|r|r|r|r|}
\hline \multicolumn{6}{|c|}{ Frecuencia de viaje al resguardo de origen de algún miembro del hogar } \\
\hline Frecuencia/Cabildo & Yanacona & Nasa & Quichua & Inga & Kofán & Guambiano \\
\hline Varias veces al mes & 1,1 & 3,8 & 3,4 & 3,3 & 11,1 & 20,0 \\
\hline Una vez al mes & 2,3 & 7,1 & 6,9 & 3,3 & 11,1 & 20,0 \\
\hline Varias veces al año & 37,6 & 37,2 & 13,8 & 23,3 & 50,0 & 34,3 \\
\hline Una vez al año & 46,0 & 39,7 & 65,5 & 51,7 & 27,8 & 22,9 \\
\hline $\begin{array}{l}\text { Menos de una vez al } \\
\text { año }\end{array}$ & 12,9 & 12,1 & 10,3 & 18,3 & 0,0 & 2,9 \\
\hline Total & 100,0 & 100,0 & 100,0 & 100,0 & 100,0 & 100,0 \\
\hline
\end{tabular}

Fuente: Motta, Posso, Estudio Etnológico, 2007. Trabajo de campo

Todos los cabildos urbanos recrean diversas prácticas culturales ancestrales en el entorno de la ciudad, actividades que generan construcción, recreación, permanencia y resistencia de manifestaciones o hechos culturales. En la tabla 5 se resalta la importancia de la comida tradicional en todos los cabildos con porcentajes entre el 14 y el $25 \%$ de los hogares. Otro elemento de gran relevancia para los hogares étnicos son los saberes médicos tradicionales que oscilan entre porcentajes del 14 al $23 \%$. Una tercera práctica es la tradición 
oral, los mitos, leyendas y relatos de la cultura tradicional que se recrean, con porcentajes de frecuencia entre el 13 y $16 \%$. En cuarto lugar, encontramos relativamente frecuente en hogares de todos los cabildos, la práctica del tejido tradicional con porcentajes entre el 10 y el $15 \%$.

Tabla 5. Prácticas culturales en el hogar por cabildo

\begin{tabular}{|c|c|c|c|c|c|c|}
\hline \multicolumn{7}{|c|}{ Prácticas culturales en el hogar } \\
\hline Práctica/Cabildo & Yanacona & Nasa & Quichua & Inga & Kofán & Guambiano \\
\hline $\begin{array}{l}\text { Práctica de la danza } \\
\text { tradicional en el } \\
\text { hogar }\end{array}$ & $8,4 \%$ & $7,5 \%$ & $14,4 \%$ & $7,8 \%$ & $11,9 \%$ & $9,5 \%$ \\
\hline $\begin{array}{l}\text { Práctica de la } \\
\text { música tradicional } \\
\text { en el hogar }\end{array}$ & $4,8 \%$ & $7,5 \%$ & $14,4 \%$ & $5,3 \%$ & $11,9 \%$ & $7,0 \%$ \\
\hline $\begin{array}{l}\text { Práctica de la } \\
\text { pintura tradicional } \\
\text { en el hogar }\end{array}$ & $2,5 \%$ & $5,1 \%$ & $2,9 \%$ & $4,4 \%$ & $4,0 \%$ & $5,1 \%$ \\
\hline $\begin{array}{l}\text { Práctica del tejido } \\
\text { tradicional en el } \\
\text { hogar }\end{array}$ & $12,4 \%$ & $10,8 \%$ & $15,1 \%$ & $12,8 \%$ & $11,9 \%$ & $12,7 \%$ \\
\hline $\begin{array}{l}\text { Práctica de la talla } \\
\text { tradicional en el } \\
\text { hogar }\end{array}$ & $2,5 \%$ & $1,9 \%$ & $1,4 \%$ & $2,8 \%$ & $4,8 \%$ & $2,5 \%$ \\
\hline $\begin{array}{l}\text { Trabajo en barro o } \\
\text { cerámica tradicional } \\
\text { en el hogar }\end{array}$ & $3,4 \%$ & $2,4 \%$ & $18,7 \%$ & $3,4 \%$ & $2,4 \%$ & $0,6 \%$ \\
\hline $\begin{array}{l}\text { Comida tradicional } \\
\text { en el hogar }\end{array}$ & $24,6 \%$ & $22,1 \%$ & $13,7 \%$ & $19,7 \%$ & $14,3 \%$ & $19,6 \%$ \\
\hline $\begin{array}{l}\text { Tradición oral en el } \\
\text { hogar }\end{array}$ & $15,3 \%$ & $15,9 \%$ & $7,2 \%$ & $14,7 \%$ & $12,7 \%$ & $15,8 \%$ \\
\hline $\begin{array}{l}\text { Uso de objetos } \\
\text { tradicionales } \\
\text { rituales en hogar }\end{array}$ & $5,5 \%$ & $4,3 \%$ & $12,2 \%$ & $11,6 \%$ & $12,7 \%$ & $10,8 \%$ \\
\hline $\begin{array}{l}\text { Saberes médicos } \\
\text { tradicionales }\end{array}$ & $20,7 \%$ & $22,6 \%$ & $14,4 \%$ & $17,5 \%$ & $13,5 \%$ & $16,5 \%$ \\
\hline Total & 100,0 & 100,0 & 100,0 & 100,0 & 100,0 & 100,0 \\
\hline
\end{tabular}

Fuente: Motta, Posso , Estudio Etnológico, 2007. Trabajo de campo.

Un elemento identitario transversal en la cultura de los grupos étnicos es la lengua, y el escenario predilecto en donde se practica y se recrea es la casa, luego en las fiestas o reuniones, en encuentros familiares y entre amigos y ocasionalmente en las asambleas de los cabildos. 
La lengua como marcador étnico es usada con mayor frecuencia entre los Quichuas, Ingas y Kofanes. Para Guambianos y Nasas su uso es muy bajo, aunque entre los Nasas se está viviendo un proceso de recuperar el Nasa Yuwe. Los Yanaconas que fueron los primeros migrantes a la ciudad, han perdido su lengua quechua como un panorama de discontinuidad cultural. Sin embargo, la población mayor conserva algunas palabras que hacen referencia a los eventos domésticos y familiares. Cuantitativamente en la tabla 6 se puede apreciar cómo las comunidades indígenas urbanas en un porcentaje significativo de la población mayor de 5 años, habla la lengua entre el 15 y el $74 \%$ y porcentajes mucho mayores la comprenden, entre el 39 y el $93 \%$.

A la lengua Quichua en Cali se le denomina Runacuna que es la voz de Runa c'atucuna, con variantes de Runa Simi que comparten con la etnia Ingana.

Muchos de los mayores de la comunidad no manejan bien el idioma español, pero en su actividad comercial dominan el vocabulario necesario. Hablan perfectamente lengua Quichua- Runacuna y son quienes la enseñan a sus descendientes. Los jóvenes han aprendido la lengua, pero la usan en espacios restringidos como los anteriormente mencionados: encuentros religiosos, familiares o amistosos. Por otro lado, los encuentros culturales y deportivos con la comunidad inga permiten una interacción lingüística, dadas sus afinidades en este campo. Es más frecuente que los jóvenes hablen español porque cotidianamente interaccionan con miembros de la sociedad mayoritaria. Una característica particular es que todos hacen uso de ella cuando no quieren que personas ajenas a su comunidad les entiendan.

Los datos cuantitativos del censo muestran un alto porcentaje de hablantes de la lengua Runacuna, aspecto importante en las representaciones de su identidad Quichua, como expresa el hecho de que el $66,9 \%$ de sus miembros habla la lengua, mientras que el $33,1 \%$ no lo hace, en la comprensión de la lengua se encuentra $89,3 \%$ en tanto el $10,7 \%$ no lo hace.

Así en los siguientes gráficos señalan el dominio y comprensión de la lengua Runacuna por parte de los miembros del cabildo Quichua 


\section{Gráfico 1. Dominio hablado de la lengua, según rangos de edad}

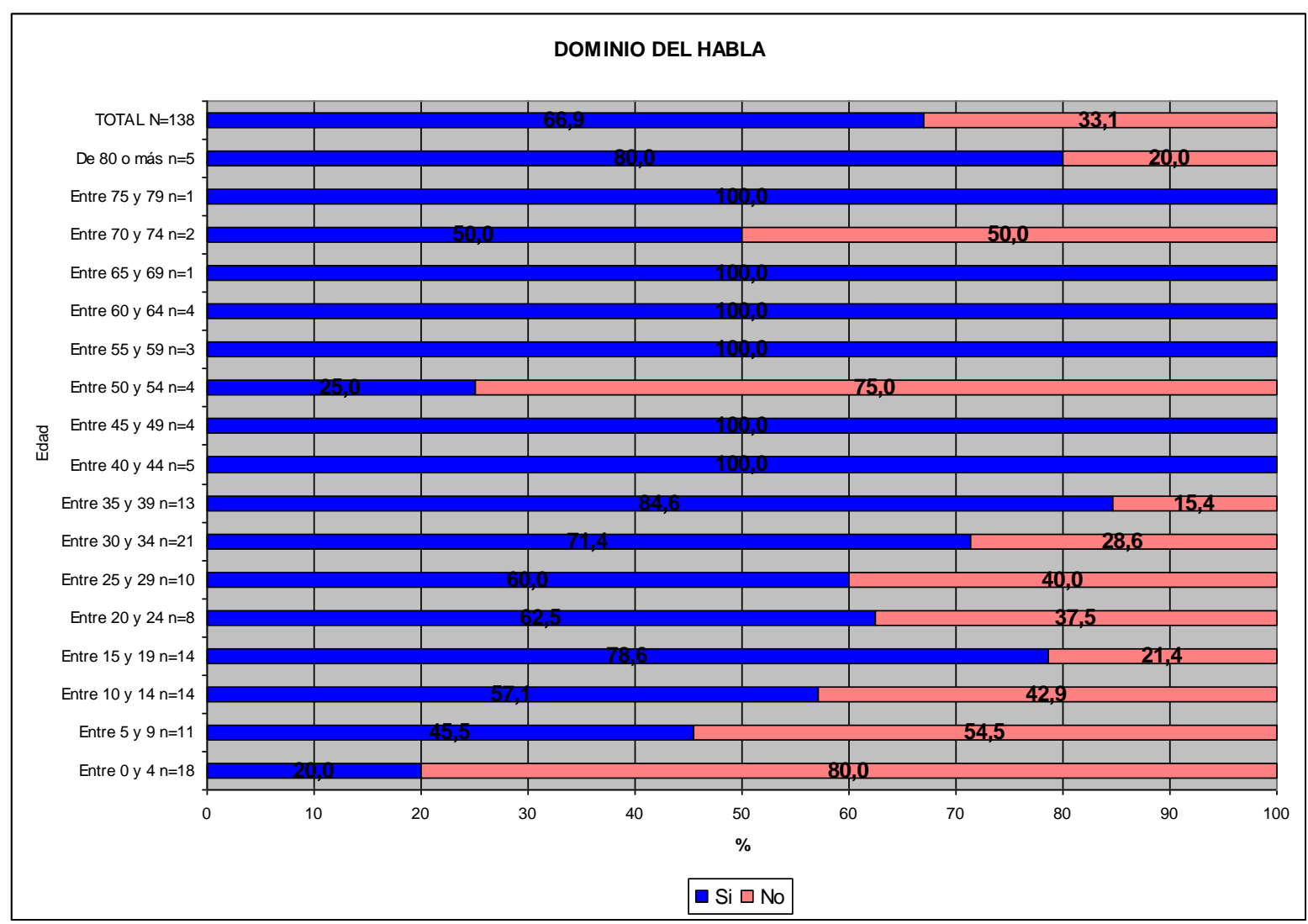

Trabajo de campo. Censo y etnografía del Cabildo Quichua. Motta y Posso. 2007

Si se compara tanto, el dominio del habla con la comprensión de la lengua, se destaca que tienen un comportamiento muy parecido en términos de que, a medida que aumenta la edad, mayor dominio del habla y la comprensión de la lengua hay (Gráficos del 1 al 3). En el caso de la comprensión se destaca que las personas mayores de 35 años tienen una comprensión total de la lengua, sin embargo, en el caso del dominio del habla se encuentra que en los rangos de edad de 35 a 39 años solo el 84,6\% habla la lengua, en el rango de 5054 solo el $25 \%$ habla lengua y en el rango de 70 y 74 años solo la mitad de la población habla la lengua tradicional de su comunidad. 


\section{Gráfico 2. Comprensión de la lengua Runacuna, según rangos de edad}

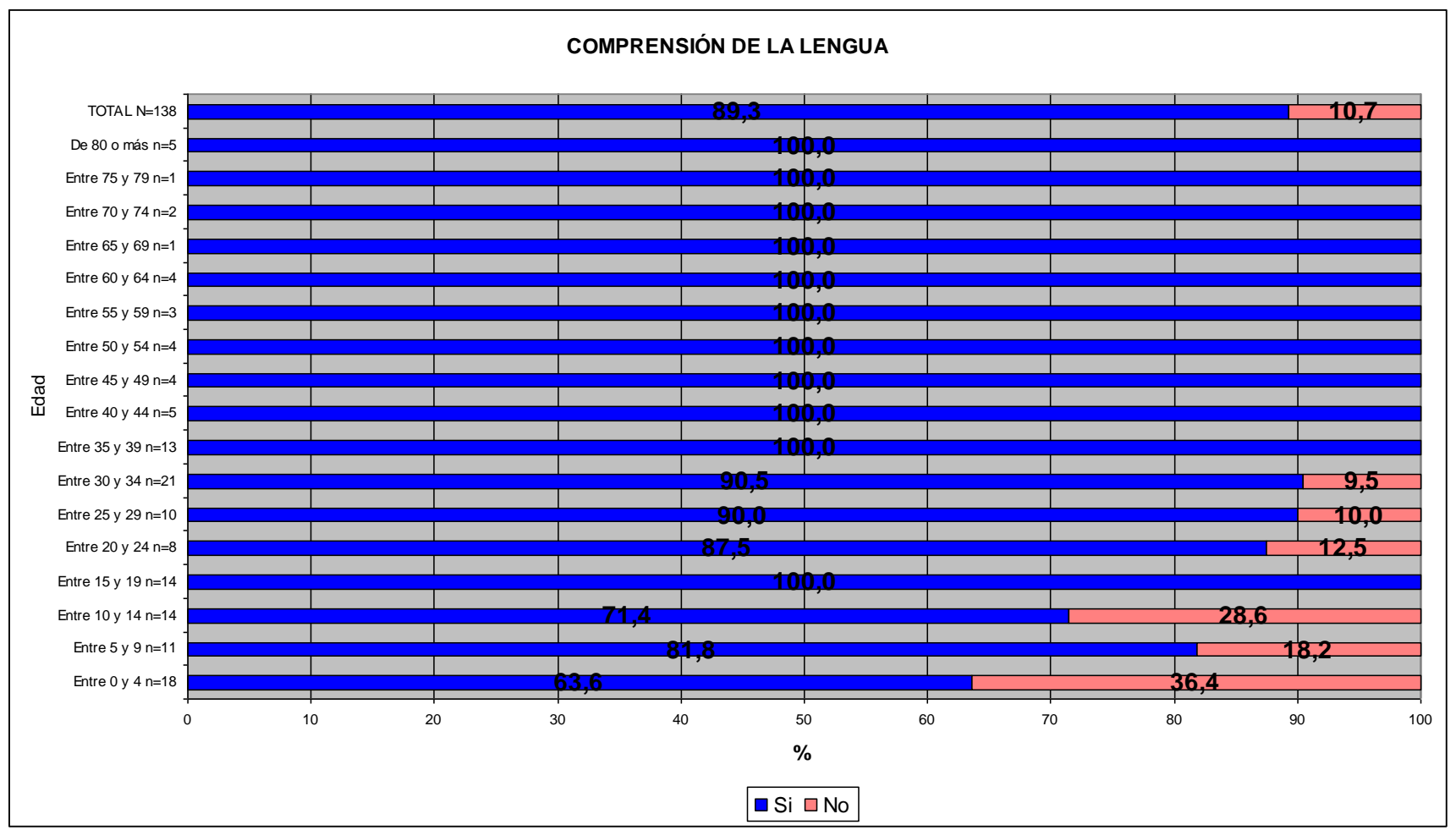

Trabajo de campo. Censo y etnografía Cabildo Quichua -. Motta y Posso. 2007.

En el gráficos 3 se comparan tanto el habla, la comprensión, la escritura y la lectura de la lengua tradicional Quechua. Se puede sugerir que la comunidad Quichua tiene un dominio total de la lengua, tanto en el habla, la escritura, la lectura y la comprensión ${ }^{5}$.

\footnotetext{
${ }^{5}$ No estoy segura de que esta lengua se escriba y se lea, porque el encuestado pudo haber entendido que se le preguntaba por el dominio de la lectura y la escritura en general y no de todo el sistema lingüístico Quechua Runacuna.
} 
Gráfico 3. Comparación del dominio del habla, la lectura, escritura y comprensión de la lengua Runacuna

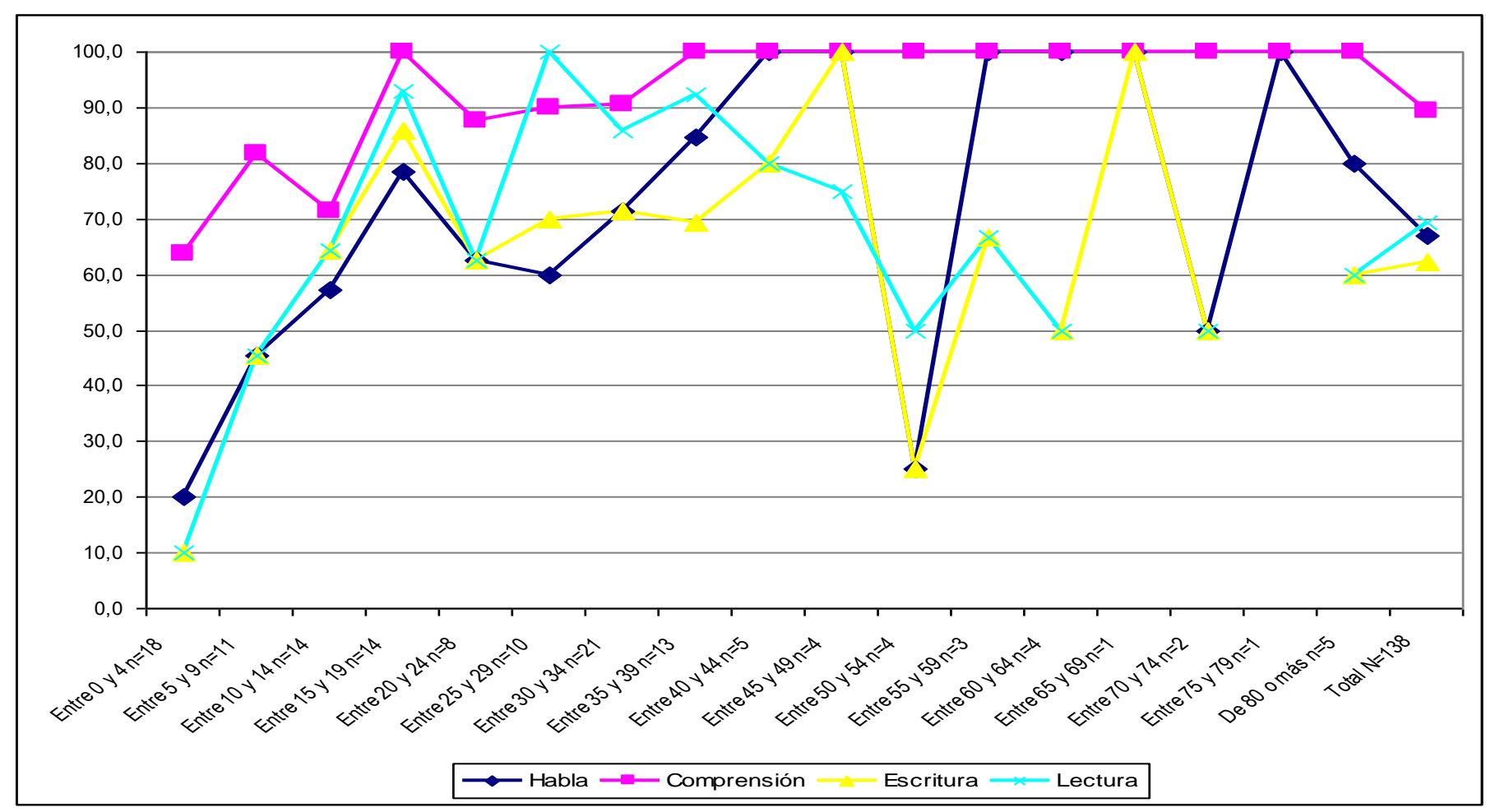

Trabajo de campo. Censo y etnografía del cabildo Quichua. Motta y Posso2007.

La tabla 6 nos muestra los porcentajes de hablantes de cada cabildo de su lengua propia.

Tabla 6. Porcentaje de personas mayores de 5 años que habla y comprende la lengua por cabildo

Dominio del habla y comprensión de la lengua de los mayores de 5 años por cabildo

\begin{tabular}{|l|r|r|r|r|r|}
\hline Cabildo & Nasa & Quichua & Inga & Kofán & Guambiano \\
\hline Habla & $4.7 \%$ & 74,2 & $39,5 \%$ & $14,8 \%$ & $16,4 \%$ \\
\hline Comprende & $9.3 \%$ & 93,3 & $57,7 \%$ & $42,0 \%$ & $39,3 \%$ \\
\hline
\end{tabular}

Fuente: Motta, Posso, Estudio Etnológico, 2007.

\subsection{Aspectos demográficos y socioeconómicos.}

Respecto al tamaño de la población de los cabildos, son los Yanaconas y Nasas los grupos con mayor número de miembros adscritos a los cabildos, le seguiría en importancia de acuerdo al número de personas los cabildos Quichua e Inga, y en último lugar los cabildos Guambiano y Kofán.

Esta población que aparece afiliada a los cabildos representa claramente al núcleo de población indígena que en la ciudad reivindican su condición étnica, 
pues no todos en la ciudad quieren ser identificados como indígenas, y, apenas comienzan en el proceso de visibilizarse y de asumirse como cabildos otros grupos étnicos como los Pastos.

La distribución de población por rangos de edad (Tabla 7) muestra a una población joven con una importante proporción de personas menores de 19 años, que en casi todos los cabildos es el porcentaje más alto de población, alrededor del $40 \%$, en segundo lugar en importancia está la cohorte entre los 20 y 39 años, es decir población en plena edad productiva, con porcentajes que varían alrededor del 35\%, lo que refleja el proceso reciente de una migración selectiva en la mayoría de los cabildos. La población adulta entre 40 y 59 años es menor pero constituye un porcentaje importante (entre el 10 y $20 \%$ ) en todos los cabildos. Los mayores de 60 años constituyen porcentajes alrededor del $7 \%$ en algunos cabildos y del $5 \%$ y menos indicando momentos diferentes del proceso migratorio.

También hay que informar que al discriminar por sexo se evidencia una predominancia del género femenino en los cabildos Ingas, Nasa, Yanaconas y Kofan, en tanto los Guambianos o Namui Misag y los Quichuas, predomina el género masculino.

Tabla 7. Distribución de la población por rangos de edad en cada cabildo

\begin{tabular}{|c|c|c|c|c|c|c|c|c|c|c|c|c|c|c|}
\hline \multicolumn{15}{|c|}{ Distribución de la población por rangos de edad } \\
\hline \multirow{2}{*}{$\begin{array}{l}\text { Rango } \\
\text { s de } \\
\text { edad }\end{array}$} & \multicolumn{2}{|c|}{ Total } & \multicolumn{2}{|c|}{$\begin{array}{c}\text { Yanacon } \\
a\end{array}$} & \multicolumn{2}{|c|}{ Nasa } & \multicolumn{2}{|c|}{$\begin{array}{c}\text { Quichu } \\
\text { a }\end{array}$} & \multicolumn{2}{|c|}{ Inga } & \multicolumn{2}{|c|}{ Kofán } & \multicolumn{2}{|c|}{$\begin{array}{c}\text { Guambia } \\
\text { no }\end{array}$} \\
\hline & $\mathrm{N}^{\circ}$ & $\%$ & $\mathrm{~N}^{\circ}$ & $\%$ & $\mathrm{~N}^{\circ}$ & $\%$ & $\mathrm{~N}^{\circ}$ & $\%$ & $\mathrm{~N}^{\circ}$ & $\%$ & $\begin{array}{c}N \\
0\end{array}$ & $\%$ & $\mathrm{~N}^{\circ}$ & $\%$ \\
\hline 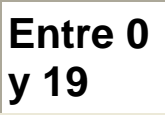 & \begin{tabular}{|r|}
146 \\
6
\end{tabular} & 40,3 & 546 & 37,2 & 628 & 42,5 & 57 & 41,3 & $\begin{array}{r}13 \\
9\end{array}$ & 44,4 & $\begin{array}{l}3 \\
5\end{array}$ & 38,0 & 61 & 41,2 \\
\hline & $\begin{array}{r}116 \\
9\end{array}$ & 32,2 & 486 & 33,1 & 426 & 28,8 & 52 & 37,7 & $\begin{array}{r}11 \\
8\end{array}$ & 37,7 & $\begin{array}{l}3 \\
5\end{array}$ & 38,0 & 52 & 35,1 \\
\hline $\begin{array}{l}\text { ntre } \\
0 \text { y } 59\end{array}$ & 43 & 20,4 & 312 & 21,3 & 329 & 22,3 & 16 & 11,6 & 44 & 14,1 & $\begin{array}{l}1 \\
6\end{array}$ & 17,4 & 26 & 17,6 \\
\hline $\begin{array}{l}60 \text { y } \\
\text { más }\end{array}$ & 207 & 5,7 & 100 & 3 & 74 & 0 & 10 & ,2 & 10 & 3,2 & 4 & ,4 & 9 & 6 \\
\hline $\begin{array}{l}\text { No } \\
\text { sabe, } \\
\text { no } \\
\text { respon }\end{array}$ & 50 & 1,4 & 3 & 1,6 & 20 & 4 & 3 & 2 & 2 & 0,6 & 2 & 2,2 & 0 & 0,0 \\
\hline Tota & \begin{tabular}{|r|}
363 \\
5
\end{tabular} & $\begin{array}{l}100 . \\
0\end{array}$ & $\begin{array}{r}146 \\
7\end{array}$ & $\begin{array}{r}100 \\
0\end{array}$ & $\begin{array}{r}147 \\
7\end{array}$ & $\begin{array}{r}100, \\
0\end{array}$ & $\begin{array}{r}13 \\
8\end{array}$ & $\begin{array}{r}100, \\
0\end{array}$ & $\begin{array}{r}31 \\
3\end{array}$ & $\begin{array}{l}100 \\
0\end{array}$ & $\begin{array}{l}9 \\
2\end{array}$ & $\begin{array}{r}100, \\
0\end{array}$ & $\begin{array}{r}14 \\
8\end{array}$ & $\begin{array}{r}100 \\
0\end{array}$ \\
\hline
\end{tabular}

Fuente: Motta, Posso, Estudio Etnológico, 2007. 
En relación al nivel educativo (Tabla 8) en general se puede señalar que se trata de poblaciones con bajos niveles de educación en las cuales un porcentaje todavía alto apenas ha cursado la primaria, valoraciones que se mueven entre el 26,7 y el $56,1 \%$. Así mismo, porcentajes significativos en algunos cabildos no han alcanzado ningún nivel educativo, como es el caso de los cabildos Quichua, Kofán e Inga con cifras respectivas del 14.6\%, $9.1 \%$ y $7.0 \%$. No obstante, se debe resaltar que excepto en el cabildo Quichua, en los cabildos restantes más del $30 \%$ de sus miembros han llegado a algún grado de educación secundaria, siendo el porcentaje más alto el de los Yanaconas con el $44.6 \%$. Respecto a la educación técnica y universitaria se presentan situaciones diversas, pero en general que muestran que sólo una pequeña proporción de la población indígena organizada en la ciudad posee educación técnica y universitaria. Los porcentajes más altos de educación técnica y universitaria se presentan en los cabildos Kofán y Guambiano, que son precisamente los que demográficamente están menos representados en Cali.

Tabla 8. Último nivel educativo aprobado de los miembros del hogar por cabildo

\begin{tabular}{|l|r|r|r|r|r|r|}
\hline \multicolumn{7}{|c|}{ Último nivel educativo aprobado del miembros del hogar } \\
\hline $\begin{array}{l}\text { Nivel } \\
\text { educativo/Cabildo }\end{array}$ & Yanacona & Nasa & Quichua & Inga & Kofán & Guambiano \\
\hline Ninguno & 3,3 & 5,3 & 14,6 & 7,0 & 9,1 & 4,8 \\
\hline Preescolar & 3,9 & 2,0 & 4,1 & 2,1 & 3,4 & 6,8 \\
\hline Primaria & 38,7 & 40,1 & 56,1 & 46,7 & 26,1 & 26,7 \\
\hline Bachillerato & 44,6 & 44,4 & 24,4 & 35,5 & 31,8 & 43,2 \\
\hline Técnico/Tecnólogo & 3,7 & 3,3 & 0,0 & 4,5 & 4,5 & 6,2 \\
\hline Universitario & 4,9 & 4,1 & 0,8 & 4,2 & 20,5 & 12,3 \\
\hline Postgrado & 0,1 & 0,1 & 0,0 & 0,0 & 3,4 & 0,0 \\
\hline No sabe/No responde & 0,8 & 0,6 & 0,0 & 0.0 & 1,1 & 0,0 \\
\hline Total & 100,0 & 100,0 & 100,0 & 100,0 & 100,0 & 100,0 \\
\hline
\end{tabular}

Fuente: Motta, Posso, Estudio Etnológico, 2007.

Las etnografías de cada uno de los cabildos urbanos dan cuenta del universo fáctico, real y simbólico, de las condiciones materiales de vida de los grupos étnicos en estudio, las actividades productivas, laborales y económicas, la distribución y el consumo, nivel de ingresos y egresos y el índice de calidad de vida. Estos datos nos permitieron analizar las estrategias de supervivencia en la ciudad y cuál es la manera de acceder a réditos y demás servicios que ofrece el estado y la institucionalidad propia de la ciudad (el municipio, las diversas instituciones públicas y privadas, las ONGs, etc.)

Estos inmigrantes indígenas procedentes de territorios de resguardo han tenido una relación directa con la naturaleza, con la tierra y con las unidades de producción de sus parcelas, ligadas a la familia. Un elemento importante en 
las mentalidades de los miembros de los cabildos indígenas urbanos es su independencia en el establecimiento de sus decisiones económicas. Este criterio cobra vigencia en el espacio urbano de Cali pues la significación de "trabajador independiente", les permite circular entre una serie de actividades productivas en la oferta laboral de la ciudad.

Los datos empíricos del operativo censal que se realizó en el año 2007, muestran una correlación de venta de fuerza de trabajo en calidad de empleados y las actividades de trabajador independiente o por cuenta propia según el criterio del DANE. (Ver tabla 9).

Tabla 9. Empleo por categoría ocupacional

\begin{tabular}{|l|r|r|r|r|r|r|}
\hline \multicolumn{7}{|c|}{ Empleo por categoría ocupacional } \\
\hline $\begin{array}{l}\text { Categoría } \\
\text { ocupacional/Cabildo }\end{array}$ & Yanacona & Nasa & Quichua & Inga & Kofán & Guambiano \\
\hline Empleado & 55,6 & 57,0 & 7,3 & 31,6 & 59,4 & 52,2 \\
\hline Patrón, empleador & 2,0 & 1,8 & 3,7 & 0,0 & 0,0 & 1,4 \\
\hline $\begin{array}{l}\text { Trabajador por } \\
\text { cuenta propia }\end{array}$ & 28,4 & 25,2 & 74,4 & 50,6 & 37,5 & 39,1 \\
\hline $\begin{array}{l}\text { Empleado (a) } \\
\text { doméstico (a) }\end{array}$ & 10,7 & 10,4 & 0,0 & 7,5 & 0,0 & 4,3 \\
\hline $\begin{array}{l}\text { Trabajador familiar } \\
\text { sin remuneración }\end{array}$ & 3,1 & 3,3 & 14,6 & 9,2 & 0,0 & 2,9 \\
\hline No sabe/No responde & 0,3 & 2,2 & 0,0 & 1,1 & 3,1 & 0,0 \\
\hline Total & 100,0 & 100,0 & 100,0 & 100,0 & 100,0 & 100,0 \\
\hline
\end{tabular}

Fuente: Motta, Posso, Estudio Etnológico, 2007

Los sectores o ramas de actividad económica en los que laboran los grupos estudiados son principalmente servicios comunales, sociales y personales; comercio, restaurantes y hoteles; industria manufacturera y la construcción. En el primer sector mencionado, con porcentajes que oscilan entre el 20 y el $50 \%$ las actividades más comunes son el servicio doméstico y el cuidado de personas mayores realizadas por las mujeres; los servicios de vigilancia y conserjería en edificios y casas particulares, jardinería y servicios varios entre otros.

Yo estoy acá hace un año largo, pero antes había venido como interna, la que me ayudó fue mi mamá que tenía unas amigas aquí desde hacía tiempo y ellas fueron las que me conectaron, pero después uno ya conoce otra gente y ellas le van informando a uno que en tal parte fulana se retiró y si uno está aburrido donde está entonces cambia de trabajo. Esa vez trabajé con una señora sola, yo la cuidaba porque ya estaba más bien ancianita, pero no podía viajar a Silvia porque ella no me dejaba, y no aguanté mucho tiempo eso, por eso cambié de trabajo, no fue 
difícil porque como le digo uno va conociendo otras empleadas y ya uno no se vara...[Entrevista a Yolanda, agosto de 2007]

Cuidar dos niños uno tenía dos años y medio y el otro un año y medio, allí también el trato de los señores era bueno, bien pero no me gustaba era, bueno yo sabia a lo que vine, pero no me gustaban los niños, no es que no me gusten si no que, como que los niños de la ciudad son muy cansones, entonces uno como que se cansa por todo y a las tres semanas me fui a una casa de familia en Bogota. En Bogotá en una floristería como operaria. (Entrevista a Tania. Mujer misak), Septiembre 2007).

En la rama comercial encontramos actividades de venta ambulante y estacionaria en la calle, pequeños locales comerciales, tiendas de barrio, hasta quienes trabajan como empleados en establecimientos del comercio. Ingas, Kofanes, Quichuas y Yanaconas sobresalen en esta actividad con unos porcentajes entre el 20 y $55 \%$ de ocupación.

Mención especial entre las actividades por cuenta propia y de comercio diferencial constituyen los grupos étnicos Ingas, Quichuas y Kofanes. La economía étnica de los Ingas se representa en el "puesto" con la venta de plantas medicinales y productos curativos mágico-religiosos. Su inserción a la economía informal como vendedores ambulantes se articula a formas de curanderismo urbano cuya fuente es su conocimiento médico tradicional. El manejo y comercialización de las plantas medicinales a través del puesto, es una recreación cultural de la chagra del espacio rural que se sustituye en el ámbito urbano y que le da significado a la existencia identitaria de los inganos en la ciudad. Es un microcosmos donde se encuentran todos los elementos míticos que preserva como guardián y dinamiza las relaciones interétnicas.

El manejo de las plantas es un saber ancestral y es una práctica cultural que se aprende y se transmite de una generación a otra. Veamos algunos relatos de este aprendizaje:

Mi abuelo era taita, entonces yo cuando estaba pequeña me iba detrás de él y le ayudaba con sus remedios, a prepararlos, él me fue enseñando lo de las plantas y así, él fue quien me ayudó a ser mama, que es como le llaman a las mujeres que trabajan con la medicina tradicional, a los hombres taitas y a las mujeres mamas, pero a mi no me gusta que me digan así, sino por mi nombre, en el Putumayo hay mamas que dan el remedio (yagé) para ser médica uno tiene que tener vocación (Entrevista con la Mama Ana Quinchoa).

El abuelo de Domingo era un médico bastante afamado en Santiago, del él aprendió todas las artes de la sanación a través de la lectura de la orina, las medicinas y purgas, el yagé y los corales. Domingo cuenta sobre la experiencia de iluminación y aprendizaje de "todos los secretos" de sanación que le fueron otorgados durante una toma solitaria de yagé que realizó hace tiempo, en este momento que fue 
bastante duro y peligroso el yagé le transfirió todas las herramientas que él necesitaba para saber manejar las plantas, la adivinación y la suerte, después del evento el taita "supo" (Diario de campo visita al Taita Domingo Quinchoa) $)^{6}$.

El trabajo para un Inga de la ciudad determina sus relaciones con ella ya que el "puesto" de venta de hierbas y plantas medicinales, se encuentra inmerso en las dinámicas del centro, donde funciona todo su movimiento comercial, estos puestos construyen y se disputan por un lugar dentro de la geografía de la ciudad, resignifican los espacios a través de practicas identitarias diferenciadas de otras ventas ambulantes, y, de otro lado, son la fuente de ingresos para sacar a las familias adelante, dar estudio a los hijos, pagar arrendamientos 0 comprar casa y sobre todo asegurar una estabilidad para la familia. La calle como lugar de la actividad económica vital ha implicado que la etnia ingana haya acumulado una experiencia laboral de colocar su puesto en un espacio y establezca redes de intercambio entre el mundo de los individuos urbanos y el mundo de la comunidad étnica:

[...] Era duro, nos tocó duro porque nosotros no conocíamos, habíamos pasado por aquí pero nunca había trabajado, sin embargo aquí vivía un familiar y nos dijo si les gusta quédense aquí y si no te gusta te vas para Bogotá, porque yo estaba aquí de paso porque yo iba para Bogotá donde siempre he trabajado desde unos 15 años, me quedé y me ha tocado muy duro porque yo no tenía conocimiento del trato y del manejo hacia la gente. (Entrevista con el Taita José Jacanamejoy).

Efectivamente el puesto de ventas y todo lo que él contiene si bien obedece a una estrategia de supervivencia de los indígenas en la ciudad, también posee ciertos rasgos de orden cultural y ancestral que deben tomarse en cuenta.

Los Quichuas se han especializado en la comercialización de prendas de vestir, especialmente de lana, aunque no necesariamente son productos artesanales. Su actividad comercial se ha desarrollado bajo las modalidades del puesto fijo, el "caseo" (Motta, 2004) de venta en el mismo lugar de la vivienda.

El grupo étnico Kofán se distingue por un tipo de actividad que se ha configurado como economía étnica, dado que es controlada totalmente por el cabildo, pero cuyos beneficios mayoritariamente van destinados a miembros de la comunidad de origen y particularmente a los taitas o curacas para que la oficien. Tal actividad es el ritual de las tomas de Yagé cada quince días en Cali, actividad legalizada por la secretaría de salud municipal. La ingesta del

\footnotetext{
${ }^{6}$ Puesto que no todos los entrevistados aceptaron el uso de la grabadora se referencia el diario de campo cuando no ha sido posible grabar la entrevista.

${ }^{7} \mathrm{La}$ actividad del casear es una labor eminentemente femenina y consiste en la apropiación del espacio público- la calle- en donde comercia la mercancía en lana expendiéndola de puerta a puerta. Esta movilidad espacial en la ciudad implica desplazarse a pie llevando a cuestas la mercancía. Se efectúan inicialmente cerca de los barrios donde residen y, a medida que van conociendo la ciudad, las distancias que recorren las mujeres se van ampliando, sin alejarse mucho del perímetro del territorio donde se localizan.
} 
Yagé tiene un alto contenido simbólico y sigue los pasos de la realización del ritual tal como lo han planteado Gutiérrez (2002) y Perrin (2007) en ceremonias chamánicas en América Latina.

El empleo en la industria tiene una representatividad importante en cabildos pequeños como el Kofán y Guambiano, en los que alcanza porcentajes alrededor del $20 \%$, en tanto en el área de la construcción los Yanaconas y Nasas lo desempeñan en un 10\% (Ver tabla 10).

Tabla 10. Empleo por rama de actividad económica y cabildo Empleo por rama de actividad económica

\begin{tabular}{|c|c|c|c|c|c|c|}
\hline $\begin{array}{l}\text { Rama de actividad } \\
\text { /Cabildo }\end{array}$ & Yanacona & Nasa & Quichua & Inga & Kofán & Guambiano \\
\hline $\begin{array}{l}\text { Agricultura, caza, } \\
\text { silvicultura y pesca }\end{array}$ & 1,5 & 1,2 & 0,0 & 0,6 & 6,3 & 6,0 \\
\hline $\begin{array}{l}\text { Explotación de minas } \\
\text { y canteras }\end{array}$ & 0,2 & 3 & 0,0 & 0,0 & 0,0 & 0,0 \\
\hline $\begin{array}{l}\text { Industrias } \\
\text { manufactureras }\end{array}$ & 10,7 & 11,0 & 0,0 & 7,2 & 18,8 & 20,9 \\
\hline $\begin{array}{l}\text { Electricidad, gas y } \\
\text { agua }\end{array}$ & 0,6 & 1,0 & 0,0 & 0,6 & 0,0 & 0,0 \\
\hline Construcción & 9,9 & 13,2 & 0,0 & 9,0 & 3,1 & 4,5 \\
\hline $\begin{array}{l}\text { Comercio al por } \\
\text { mayor y al por } \\
\text { menor, y } \\
\text { restaurantes y } \\
\text { hoteles }\end{array}$ & 28,5 & 18,6 & 97,6 & 54,8 & 6,3 & 31,3 \\
\hline $\begin{array}{l}\text { Transportes, } \\
\text { almacenamiento y } \\
\text { comunicaciones }\end{array}$ & 3,7 & 3,2 & 0,0 & 3,0 & 12,5 & 6,0 \\
\hline $\begin{array}{l}\text { Establecimientos } \\
\text { financieros, seguros, } \\
\text { bienes inmuebles y } \\
\text { servicios prestados a } \\
\text { las empresas }\end{array}$ & 1,4 & 2,7 & 0,0 & 0,6 & 0,0 & 3,0 \\
\hline $\begin{array}{l}\text { Servicios comunales, } \\
\text { sociales y personales }\end{array}$ & 38,2 & 41,2 & 2,4 & 22,3 & 50,0 & 28,4 \\
\hline No sabe/No responde & 5,3 & 7,5 & 0,0 & 1,8 & 3,1 & 0,0 \\
\hline Total & 100,0 & 100,0 & 100,0 & 100,0 & 100,0 & 100,0 \\
\hline
\end{tabular}

Fuente: Motta, Posso, Estudio Etnológico, 2007.

La diferencia étnica en las actividades económicas que desarrollan estos tres grupos estudiados (Ingas, Quichuas y Kofanes) les ha permitido configurar determinados nichos de mercado en lo que se ha conocido en la literatura 
sobre este tema como "economías étnicas" o "enclaves étnicos" (Bonacich y Modell, 1980; Huber, 1997; Driscoll, 2001).

Las comunidades Yanaconas, con sus chirimías y los Nasa con el trueque, encontraron otro tipo de estrategia económica. Estas comunidades no parten del desarrollo en la ciudad de una economía étnica como tal, sino que intentan crearla de forma planificada a partir de la ventaja que les da el proceso organizativo en la ciudad como cabildo indígena.

En relación a la distribución espacial de los hogares de los seis cabildos indígenas estudiados y la distribución socioeconómica en Cali, se muestra una polarización social, en la que los estratos bajos y medios (uno a tres) se localizan en la periferia occidental y oriental de la ciudad, cercando un corredor central Sur - Norte en el que se ubican los estratos altos (4 a 6) Las empleadas domésticas especialmente las Nasas que por su lugar de trabajo, se localizan en los estratos altos, reportan tal estrato socioeconómico en la dinámica socio espacial.

En general los indígenas que están organizados en cabildos en la ciudad de Cali pertenecen a un nivel socioeconómico medio bajo y bajo. Las viviendas se encuentran situadas en su gran mayoría en los estratos 1 al 3, y en porcentajes muy bajos en los estratos cuatro y cinco. Las situaciones de pobreza más acusada se evidencian en los cabildos de población más numerosa como los Nasa y Yanacona en los que alrededor del $80 \%$ de las viviendas están situadas en los estratos 1 y 2 . En otros cabildos como el Inga y Kofán el estrato de la vivienda no revela la situación de hacinamiento que viven muchos de sus miembros al habitar inquilinatos.

En el proceso de adaptación a la ciudad de Cali, los Ingas buscan sitios inicialmente céntricos para vivir, o en lugares donde puedan comercializar sus plantas medicinales, por ello escogen zonas cercanas a las plazas de mercado. Cuando aprenden a manejar el espacio urbano buscan otros lugares de vivienda no distantes del centro de la ciudad; es en la zona geoespacial del centro oriental de Cali, donde los inganos se han establecido.

Los Nasas tienen un patrón de residencia disperso con una tendencia espacial hacia el oriente de Cali donde se localizan barrios de estrato 1. Para los Namui Misag (Guambianos) la concentración de población se localiza en dos áreas, una en el extremo occidental y la otra en el extremo oriental de la ciudad, cuyas viviendas se localizan en sectores populares y de uso exclusivamente residencial en estratos 1 y 2 .

Al igual que los Ingas, el pueblo Quichua se ubica en la zona central de la ciudad, cuyo estrato corresponde al tres, lugar de múltiples actividades, en la que se presenta comercio al detalle, residencia popular en decadencia y patrimonial institucional, ámbito apropiado para el desarrollo de sus prácticas comerciales de sobrevivencia.

Los Yanaconas se localizan en sector occidental de Cali en zona de ladera ubicada en el pie de monte de los farallones y también en sector oriental de la ciudad en lo que se denomina la llanura de inundación del río Cauca. Sus 
viviendas asentadas en áreas residenciales populares de bajo estrato socioeconómico, que va desde sin estrato hasta el dos, tienen una similaridad con el patrón de residencia Namui Misag.

La distribución espacial de los Kofanes no presenta patrones reconocibles en la ciudad, lo cual puede deberse a que sus procesos migratorios campo-ciudad son más recientes. Sin embargo, en las visitas domiciliarias para el registro etnográfico se pudo observar que se ubican en los estratos socioeconómico dos y tres, que corresponde a la clase media baja (Ver tabla 11).

Tabla 11. Estrato socioeconómico de las viviendas por cabildo

\begin{tabular}{|l|r|r|r|r|r|r|r|}
\hline \multicolumn{7}{|c|}{ Estrato socioeconómico de las viviendas } \\
\hline Estrato/Cabildo & Yanacona & Nasa & Quichua & Inga & Kofán & Guambiano \\
\hline Subnormal & 0,9 & 3,9 & 0,0 & 0.0 & 0,0 & 0,0 \\
\hline Estrato 1 & 56,4 & 49,9 & 11,8 & 34,9 & 0,0 & 34,9 \\
\hline Estrato 2 & 31,2 & 25,7 & 2,9 & 22,9 & 31,8 & 30,2 \\
\hline Estrato 3 & 7,8 & 13,1 & 61,8 & 33,7 & 59,1 & 25,6 \\
\hline Estrato 4 & 0,9 & 1,2 & 0,0 & 0,0 & 4,5 & 9,3 \\
\hline Estrato 5 & 0,6 & 0,3 & 0,0 & 1,2 & 0,0 & 0,0 \\
\hline No registra & 2,3 & 6,0 & 23,5 & 7,2 & 4,5 & 0,0 \\
\hline Total & 100,0 & 100,0 & 100,0 & 100,0 & 100,0 & 100,0 \\
\hline
\end{tabular}

Fuente: Motta, Posso, Estudio Etnológico, 2007

Igualmente la ubicación espacial de los hogares de los cabildos descritos en la ciudad de Cali, se observa en el siguiente mapa: 


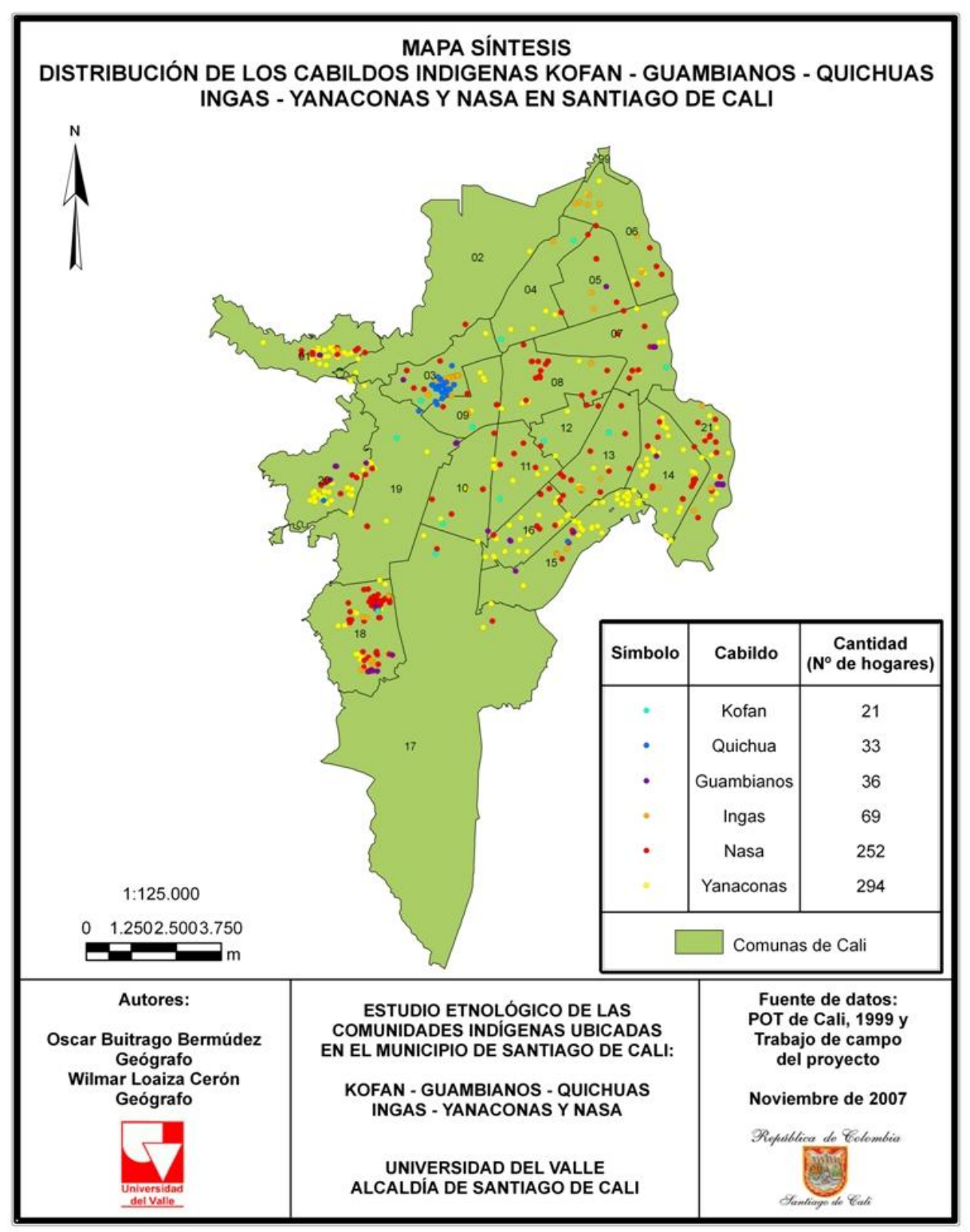

Fuente: Motta, Posso, Estudio Etnológico, 2007

\section{La construcción de la identidad en el contexto urbano}

\subsection{Cabildo Inga}

Los elementos constitutivos de la cultura Inga asentada en Cali se pueden sintetizar en los siguiente puntos: 1 ) los puestos de ventas que representan y sintetizan claramente los valores del trabajo familiar, la medicina, los Taitas y Mamas y la migración inga culturalmente organizada; 2) los valores de la casa y el manejo de la espacialidad para la realización de las prácticas identitarias; 3) las redes parentales de filiación y descendencia y la organización de sus estructuras de parentesco afín, consanguíneo y ritual; 4) las redes de reciprocidad, del don y ayuda mutua muy marcadas; 5) el uso de la lengua materna y el pensamiento que ella genera tanto en las familias tronco o focales de migración, como en las nuevas generaciones ingas nacidas en Cali; 6) la presencia de Taitas y Mamas en la organización del cabildo; 7) el trabajo como 
fuerza colectiva de supervivencia material e identitaria; 8) los retornos a los lugares de origen para celebrar festejos rituales y religiosos y la oportunidad de circulación de conocimiento y prácticas ingas que esto le trae al ambiente urbano; y, 9) el cabildo organizado con asambleas permanentes, una junta directiva, unos parámetros claros de organización y un cronograma de integración comunal.

\subsection{Cabildo Nasa}

El cabildo Nasa ha agenciado una forma de socialización y reinvención de la identidad en la ciudad haciendo uso de estrategias como el conocimiento jurídico tanto ancestral como institucional, la lucha por la visibilización de la diferencia cultural, el deseo de organización de un territorio compartido en el marco urbano como proyección a futuro, la colectividad de la minga como espacio festivo, ceremonial y político, las relaciones con los cabildos de origen y el trabajo articulado con los seis pueblos indígenas habitantes de Cali.

\subsection{Cabildo Namui Misag (Guambiano)}

La apuesta de este cabildo es avanzar en su gestión política. Los vínculos de la comunidad guambiana con su origen se mantienen y constituyen un referente identitario fundamental para la comunidad urbana, expresión de ello es el uso generalizado de la lengua materna entre los más jóvenes.

\subsection{Cabildo Quichua}

Entre los principales componentes que evidencian una estructura comunal entre los quichuas de Cali encontramos: la constante evolución del Cabildo en su proceso organizativo que, entre otros logros, ha conseguido un reconocimiento social y político por parte de otros actores de la ciudad; su estable orden interno que los consolida como una institución más de la ciudad a través de actividades propias de su cultura; los aportes en el entramado urbano, visibles a través de su actividad comercial y artesanal principalmente y con ello la valoración del trabajo; las relaciones familiares y comerciales, que favorecen su inserción en las dinámicas propias del entorno urbano; el uso de la lengua materna y las relaciones de reciprocidad evidentes en su entorno social; las variantes de sus redes de parentesco puestas en práctica y los vínculos con sus orígenes y, finalmente, el significativo papel desempeñado por la Iglesia Evangélica, como un factor de renovación de sus estructuras ancestrales dentro de una sólida organización

\subsection{Cabildo Yanacona}

La construcción cultural del Yanacona en la ciudad juega un papel importante la vivienda, donde se recrea el mundo indígena de los pueblos del Macizo Colombiano en el orden simbólico y material. Los saberes musicales - la chirimía- como forma de expresión propia, está presente en todas las esferas de su mundo religioso, político y social. Su proceso organizativo en la ciudad de Cali, fue la base para construir su memoria histórica, su existencia política 
en el ámbito urbano y desde el cual se jalonaron los procesos políticos e identitarios de sus resguardos. Los Yanaconas han demostrado a lo largo de su historia en la ciudad una cohesión social que los identifica como grupo aun antes de su reconocimiento político. El Cabildo urbano Yanacona de Cali es una estructura organizativa fuertemente consolidada gestada desde tiempo atrás, y es por ello que mantienen el liderazgo frente a los demás Cabildos de la ciudad. La construcción de la Yanaconidad se explicita en formas diversas y complejas que en ocasiones se yuxtaponen, generando los procesos de los Yanaconas tradicionales, los Yanaconas modernos y los Yanaconas en formación (Motta, 2004).

\subsection{Cabildo Kofan}

La planta sagrada del Yagé es hito y matriz cultural de la comunidad tanto en su territorio originario como en su historia dentro de la ciudad de Cali. Esta comunidad al auto representarse y nombrarse a sí misma, lo hace poniendo en un mismo plano la vida como valor principal y al yagé como facilitador de la vida, la planta garantiza la búsqueda de un camino espiritual tanto individual como colectivo. Los mediadores y facilitadores del saber vivir bien a través de esta planta sagrada son los curacas. Por tanto, la comunidad antes que contar con líderes políticos cuenta con líderes espirituales que desde su poder y conocimiento regulan los valores del colectivo como tal.

\section{Epílogo}

El cabildo indígena, institución clave en las estructuras sociales de los territorios de resguardo en los espacios rurales, se convierte en la ciudad, en un nuevo protagonista y empieza a ser parte de la nueva historia urbana. Es en el cabildo donde se decide con palabras, las adaptaciones y el mantenimiento del corpus cultural de los grupos étnicos estudiados al nuevo medio sociocultural urbano.

El cabildo como institución ha venido desempeñándose en diversos frentes de trabajo que cubren un amplio espectro de necesidades tanto de bienestar social como del rescate de algunas tradiciones culturales; reetnización de nuevos procesos y construcción de una identidad diferencial en la ciudad. En este proceso de recuperación y fortalecimiento el cabildo tiene algunas proyecciones a futuro que se articulan alrededor de: 1) consolidación del proyecto de política indígena en la ciudad; 2) fortalecer la visibilización de los cabildos en la ciudad; 3) reivindicación de derechos de reconocimiento por parte de las instituciones departamentales y municipales de la presencia indígena urbana a nivel político.

El cabildo como estrategia política de reinvención cultural en la ciudad, como proyecto común entre los distintos grupos étnicos, ha mantenido sus vínculos con sus comunidades de origen, lo que constituye un referente identitario fundamental para la comunidad urbana. La heterogeneidad de los cabildos indígenas urbanos y sus miembros emplea diversas formas de habitar la ciudad y de la apropiación de los espacios, en fin, tejer la vida en la ciudad. La construcción del mundo indígena en la ciudad implica para las comunidades 
mantener ciertas pautas tradicionales, cambiar otras y asimilar nuevas formas para adaptarse al medio urbano.

La identidad de los grupos étnicos estudiados en el contexto de la ciudad de Cali deben entenderse como un proceso relacional, al construirse a partir de la relación de los sujetos consigo mismos y con los demás, mediante interacciones y circunstancias en las que se desenvuelven. La ciudad ha favorecido su interacción, al generarle contacto con otros individuos, en los cuales se intercambian información, conocimientos y experiencias que van nutriendo las narrativas de su identidad (Agier, 2000, p. 8). La interacción con el otro ha podido alterar el pensamiento y la personalidad, el comportamiento y valores constituyentes de sus respectivas etnias. Sin embargo, tales identidades étnicas se están reciclando continuamente en las áreas donde se asientan y en especial en el centro de la ciudad, lugar del poder simbólico, en un proceso continuo, desigual, individual y colectivo al mismo tiempo. El encuentro entre los diversos cabildos indígenas urbanos y los actores de la ciudad, les ha significado diferentes espacios, temporalidades, conductas y concepciones del mundo. Las identidades de estos grupos étnicos articulados a sus cabildos siguiendo a Cámara Barbachano (1986, p. 10) "es el resultado de un proceso histórico, cambiante, dinámico y sujeto a diferentes conocimientos y concepciones de la realidad social en la que vive el sujeto".

Para finalizar, el estudio de estas diversas comunidades étnicas articulas a sus cabildos y su vez como una organización política multiétnica, nos ha permitido reflexionar acerca de las normas, los valores, los procesos de reetnización, redefinición y apropiación de nuevas identidades, en lo cual siguiendo a Bonfil Batalla (1970 y 1982), lo propio y lo ajeno se han entretejido, o sea lo propio, las raíces culturales, el simbolismo del puesto, del Yagé, del caseo, de la minga, se han combinado con lo nuevo que ofrece la ciudad y su adaptación, tanto en la especialidad, como en los tiempos y en las prácticas citadinas, lo que implica que deben orientarse las acciones de las personas y de las instituciones que participan en las interacciones de las lógicas del mundo indio en la ciudad y es lo que se puede denominar identidades de frontera, identidades multilocales.

Todos los cabildos indígenas urbanos, constituyen identidades translocales o identidades de frontera ${ }^{8}$, porque no sólo se contempla el territorio físico y el horizonte cultural tejido entre el resguardo y la ciudad, sino que también se han ido creando comunidades simbólicas y redes de empoderamiento local, nacional o transnacional frente al modelo excluyente de modernidad del desarrollo, que pretende recolonizarlas o subaltenizarlas. Los conceptos de "pensamiento frontera", "epistemologías de frontera" , " etnografías multilocales", son nociones que abarcan en la globalización, el tiempo-espacio de las comunidades identitarias, en el sentido de cómo se combinan y se mezclan, cómo se sitúan en medio de la heterogeneidad y/o homogenización y como se remodelan una y otra vez en los circuitos con fronteras inestables o

\footnotetext{
${ }^{8}$ En el Foro Social Mundial de Porto Alegre realizado en el 2001 y en el Tercer Congreso Internacional de Latinoamericanistas en Europa, realizado en Amsterdam en julio 3-6 del 2002, el concepto de Frontera, es el episteme relevante para los nuevos imaginarios socioculturales y políticos del Tercer Mundo
} 
móviles.

Hoy como ayer, continúa el debate epistemológico de la otredad cultural que desde diversas perspectivas teóricas ha encontrado un lugar para el análisis de las interacciones, las fragmentaciones, y la transversalidad de experiencias culturales. La otredad expresada en un mundo otro, en un contexto no tan solo rural, sino también en ambientes urbanos y citadinos.

De acuerdo con Segato (1999) este estudio puede calificarse como una etnografía multilocal, es decir, una metodología antropológica a seguir en la globalización, ya que las voces de las distintas culturas deben ser escuchadas y apoyadas, para poder dar cuenta de la compleja interrelación de lo global y lo local en la teoría y en la praxis del desarrollo. Este tipo de etnografía consiste en la descripción de las múltiples versiones de desarrollo y modernidades que ejecutan los pueblos al interior de sus sistemas socioculturales en interacción con los estados- nación desde una perspectiva política endógena y cómo se articulan al proyecto cultural global de la diferencia (Motta, 2008). Ello implica analizar tanto las internalidades como las externidades de las alteridades e historias locales en el sistema mundial moderno. Los seis cabildos indígenas urbanos pujando por su inclusión en la sociedad caleña, constituyen las nuevas voces para asumirse como nuevos ciudadanos en el contexto de la heterogeneidad y de la diferencia.

\section{Fuentes documentales}

Censo cabildos indígenas urbanos. (2007). Encuesta indígena especializada de Santiago de Cali. Cali.

Chasoy, Isabel. Mama vicegobernadora del cabildo urbano de la etnia Ingana. Trabajo etnográfico y visita domiciliaria Entrevista Cali Julio de 2007.

Jacamejoy, José. Perteneciente al cabildo urbano inga. Trabajo etnográfico y visita domiciliaria. Entrevista Cali, Agosto de 2007.

Mavesoy, Emérita. Perteneciente al cabildo urbano inga. Trabajo etnográfico y visita domiciliaria. Entrevista Cali Julio de 2007.

Olinto, Cesar. Perteneciente al cabildo indígena urbano Nasa. Trabajo etnográfico y visita domiciliaria. Entrevista Cali, Agosto de 2007.

Pilin, Yolanda. Perteneciente al cabildo indígena urbano Guambiano. Trabajo etnográfico y visita domiciliaria. Entrevista Cali Agosto de 2007.

Quinchoa, Ana. Mama de la etnia Inga. Cabildo indígena urbano. Entrevista Cali Septiembre de 2007.

Quinchoa, Domingo. Taita de la etnia Inga. Cabildo indígena urbano. Entrevista Cali Septiembre de 2007.

Velasco, Adriana. Perteneciente al cabildo indígena urbano Nasa. Trabajo etnográfico y visita domiciliaria. Entrevista Cali Agosto de 2007. 
Velasco, Tania. Perteneciente al cabildo indígena urbano Guambiano. Trabajo etnográfico y visita domiciliaria. Entrevista Cali Agosto de 2007.

\section{Fuentes Bibliográficas}

Alcaldía Municipal De Cali. (2001) Plan de desarrollo municipal de Santiago de Cali.

Alcaldía Municipal De Cali. (2006) Fortalecimiento cultural y sostenibilidad a la productividad de las comunidades organizadas en cabildos en el Municipio Santiago de Cali. Cali: Secretaría de Desarrollo Territorial y Bienestar Social.

Agier, M. (2000). La antropología de las identidades en las tensiones contemporáneas. Revista Colombiana de Antropología e Historia.

Bonacich, E. y Modell J. (1980). "The economic basis of ethnic solidarity. Small Business in the Japanese American community". Berkeley: University of California.

Bonfil Batalla, G. (1970). Lo propio y lo ajeno. El control cultural de las decisiones delos pueblos indios. Revista FLACSO.

Bonfil Batalla, G. (1982). El Etnodesarrollo: sus premisa jurídicas, sociales y políticas. Revista FLACSO.

Bonilla G., R. \& Rodríguez, L. (2003). Documento sobre la situación del mercado laboral en la Ciudad de Cali y su área metropolitana. Universidad Nacional, Centro de Investigaciones para el Desarrollo CID, Ministerio de Trabajo y Seguridad Social. Recuperado el 17 de julio de 2007 del sitio web de la Universidad Nacional de Colombia: www.cid.unal.edu.co/files/publications/CID200304boproob f.pdf

Cámara Barbachano, F. (1986). Los conceptos de identidad y etnicidad. México: América Indígena.

Castillo, L. C. \& Cairou, H. (2002). Reinvención de la identidad étnica, nuevas territorialidades y redes globales: El Estado multiétnico y plurilcultural en Colombia y Ecuador. Sociedad y Economía Revista de la Facultad de Ciencias Sociales y Económicas de la Universidad del Valle, 3.

CVC - UNIVERSIDAD DEL VALLE. (2007). Plan de ordenamiento y manejo de de cuencas hidrográficas- $\mathrm{POMCH}$ - Río Cali. Informe Diagnóstico. Cali

DEPARTAMENTO NACIONAL DE ESTADISTICA-DANE. (2005). Encuesta nacional de hogares. Bogotá.

Driscoll, B. A. (2001). La actividad empresarial de la comunidad latina en Estados Unidos. Impactos y perspectivas. Problemas del Desarrollo, 32, 125. 
Essed, P. (1991). Understanding everyday racism. An interdisciplinary Theory. California: Sage Publications.

Gutierrez, A. (2002). La peregrinación a Wirkuta. Estudios monográficos. México: Instituto Nacional de Antropología e historia en México.

Huber, L. (1997). Etnicidad y economía en el Perú, Documento de Trabajo № 83. Lima: IEP Ediciones.

Koonings, K. \& Silva, P. (1999). Construcciones étnicas y dinámica sociocultural en América Latina. Quito: Abya-Yala.

Motta González, N. (2004). Con chirimías, lanas y medicinas: hombres y mujeres indígenas reinventando el cabildo e la ciudad. En Castellanos, G. (Comp). Textos y Prácticas de Género. Cali: Universidad del Valle.

Motta González, N. (2008). Territorios de frontera e historias locales: una etnografía multilocal. Revista Historia y Espacio, 30.

Motta G., N. \& Posso, J. (2007). Hacia el reconocimiento de una identidad indígena urbana en Cali." Estudio etnológico de las comunidades indígenas ubicadas en el municipio de Santiago de Cali, Kofán, Guambianos, Quichuas, Ingas, Yanaconas, Nasas. Informe final. Cali: Convenio Alcaldía de Cali y Fundación General de Apoyo a la Universidad del Valle.

Perrin, M. (2007). Las artes de los Chamanes. En Barona, F. (Comp.) Chamanismo. Tiempos y lugares sagrados. Cali: Programa Editorial Universidad del Valle.

Segato, R. L. (1999). Identidades políticas / alteridades históricas: una crítica a las certezas del pluralismo global. Revista Maguaré, 14.

Wade, P. (1987). Relaciones e identidades étnicas en el Urabá chocoano ante la presencia antioqueña y costeña. En Cifuentes, A (ed). La Participación del negro en la formación de las sociedades latinoamericanas. Bogotá: ICAN Colcultura.

Recibido: 22 de enero de 2010.

Aprobado: 11 de mayo de 2010. 